\title{
Profil Perilaku dan Pengetahuan Warga Kelurahan Dukuh Menanggal Surabaya tentang DAGUSIBU
}

\author{
Asri Wido Mukti ${ }^{1)}$, Nadia Aisah Mayzika ${ }^{2)}$ \\ ${ }^{1,2)}$ Program Studi Farmasi, Universitas PGRI Adi Buana Surabaya \\ asriwidomukti@unipasby.ac.id
}

\begin{abstract}
ABSTRAK: Masalah penyalahgunaan obat merupakan kasus yang masih banyak ditemui pada masyarakat. Berdasarkan data yang diperoleh dari survey oleh tim dosen melalui beberapa apotek di daerah Dukuh Menanggal menunjukkan bahwa banyaknya masyarakat yang membeli obat keras tanpa resep dokter, kejadian efek samping obat, penyimpanan obat yang salah dan pembuangan sampah obat yang tidak terpakai yang tidak dimusnahkan terlebih dahulu. Melalui kegiatan sosialisasi DAGUSIBU (Dapat, Gunakan, Simpan, Buang) obat diharapkan dapat meningkatkan pengetahuan warga kelurahan Dukuh Menanggal tentang macam- macam obat, bentuk sediaan obat, cara penggunaan obat, cara menyimpan dan membuang obat yang sudah tidak dipakai serta mampu menerapkan terutama tentang bagaimana cara Mendapatkan, Menggunakan, Menyimpan dan Membuang Obat dengan Baik dan benar. Metode yang digunakan adalah pengenalan masalah, pengisian kuisioner pre sosialisasi, pelaksanaan sosialisasi DAGUSIBU dengan cara penyuluhan, diskusi interaktif, pengisian kuisioner post sosialisasi dan pambagian buku saku DAGUSIBU. Dari pengisian kuisioner pre dan post sosialisasi didapatkan hasil peningkatan pengetahuan lebih dari $50 \%$ dan nilai signifikansi $\mathrm{p}$ value 0,000 yang artinya terdapat perbedaan pengetahuan yang bermakna antara sebelum dan sesudah sosialisasi. Diperlukan upaya keberlanjutan program dan pembinaan dari apoteker yang berpraktek di apotek sehingga semakin banyak masyarakat yang mengetahui tentang cara penggunaan obat yang benar.
\end{abstract}

Kata Kunci : DAGUSIBU, Pengetahuan, Perilaku, Profil.

ABSTRACT: The problem of drug abuse is still commonly found in the community. Based on data obtained from a survey by a team of lecturers through several pharmacies in the Dukuh Menanggal area, it is shown that many people buy potent drugs without a doctor's prescription, many incidences of drug side effects, wrong drug storage and unused drug waste disposal which are not destroyed first. Through DAGUSIBU (Can, Use, Save, Dispose) drug socialization activities are expected to increase the knowledge of Dukuh Menanggal village residents about the types of drugs, dosage forms, how to use drugs, how to store and dispose of drugs that are not used and are able to apply especially about how to get, use, store and dispose of medicines properly. The method used is problem recognition, pre-socialization questionnaire filling, DAGUSIBU outreach socialization by means of counseling, interactive discussion, postsocialization questionnaire filling and the distribution of DAGUSIBU pocket books. From filling out the pre and post socialization questionnaires, it was found that the increase in knowledge was more than 50\% and the significance value was p value 0,000, which means that there were significant differences in knowledge between before and after the socialization. Efforts to program sustainability and guidance from pharmacists who practice in pharmacies are needed so that more people know about the correct use of medicines.

Keywords: Behaviour, DAGUSIBU, Knowldege, Profile. 


\section{PENDAHULUAN}

Dapatkan, Gunakan, Simpan, dan Buang merupakan kepanjangan dari DAGUSIBU. Apoteker melalui Gerakan Keluarga Sadar Obat mencetuskan istilah tersebut untuk memudahkan masyarakat dalam memahami informasi-informasi tentang obat. Lebih tepatnya, slogan ini mengajak masyarakat untuk mendapatkan, menggunakan, menyimpan dan membuang obat dengan cara yang benar ${ }^{1}$. Berbagai masalah yang terkait dengan penggunaan obat masih banyak ditemui di masyarakat seperti kurangnya pengetahuan tentang penggunaan obat yang tidak rasional, penyalahgunaan obat, terjadinya efek samping obat, beredarnya obat palsu, narkoba dan bahan berbahaya lainnya, pengelolaan obat, penyimpanan obat, serta permasalahan kesehatan terkait dengan obat lainnya. Penyebab permasalahan tersebut adalah kurangnya kesadaran masyarakat akan arti pentingnya penggunaan dan pengelolaan obat yang baik. Dari hasil survey yang telah dilakukan oleh tim dosen sebelumnya menunjukkan bahwa pola perilaku warga kelurahan Dukuh Menanggal banyak yang masih belum memahami mengenai DAGUSIBU ini. Hal tersebut tercermin dari masih banyaknya warga yang membeli obat keras di apotek tanpa resep dokter, pembuangan obat kadaluwarsa yang tidak di hancurkan terlebih dahulu, dan kejadian efek samping obat. Oleh karena itu, maka diadakan kegiatan sosialisasi DAGUSIBU yang diharapkan dapat meningkatkan pengetahuan warga kelurahan Dukuh Menanggal tentang macammacam obat, bentuk sediaan obat, cara penggunaan obat, cara menyimpan dan membuang obat yang sudah tidak dipakai serta mampu menerapkan dan mendampingi masyarakat terutama tentang bagaimana Mendapatkan, Menggunakan, Menyimpan dan Membuang Obat dengan Baik dan benar.

\section{PERMASALAHAN}

Berdasarkan data yang diperoleh dari survey pada beberapa apotek di daerah Dukuh Menanggal menunjukkan bahwa banyaknya masyarakat yang membeli obat keras tanpa resep dokter, kejadian efek samping obat, penyimpanan obat yang salah dan pembuangan sampah obat yang tidak terpakai yang tidak dimusnahkan terlebih dahulu.

\section{METODE PELAKSANAAN}

Kegiatan pengabdian sosialisasi DAGUSIBU ini menggunakan metode yang menekankan keterlibatan masyarakat dalam semua kegiatan yang dilakukan. Tahapan metode ini yaitu :

1. Pengenalan masalah

Identifikasi masalah yang dihadapi mitra terkait dengan obat. Tim pelaksana kegiatan melakukan survei awal 
2. Perumusan masalah

Masalah yang dihadapi masih kurangnya pengetahuan tentang penggunaan obat, pemilihan obat, penyimpanan obat, dan pengelolaan obat sampai pada tahap membuang obat yang benar

3. Identifikasi pemecahan masalah

Tim pelaksana kegiatan melakukan diskusi dengan mitra (kelurahan Dukuh Menanggal) untuk penyelesaian masalah.

4. Pemilihan pemecahan masalah

Tim pelaksana melaksanakan pemecahan masalah yang di hadapi oleh mitra dengan memberikan penyuluhan $\mathrm{DaGuSiBu}$, penggunaan antibiotik yang rasional dan pelatihan dengan program GeMa CerMat tentang obat dan kandungannya, dosisnya, khasiatnya, cara penggunaan, efek samping.

5. Perencanaan penerapan

Perencanaan dilakukan oleh tim dosen pelaksana bersama dengan Pengurus Cabang Ikatan Apoteker Indonesia Cabang Surabaya

6. Pelaksanaan kegiatan

Kegiatan pengabdian ini dilaksanakan setelah semua perijinan dan persiapan peralatan sudah disiapkan. Kegiatan penyuluhan dilaksanakan di Aula lantai 2 Fakultas Ilmu Kesehatan Universitas PGRI Adi Buana Surabaya.

7. Pemantauan dan pengarahan kegiatan

Pemantauan dilakukan agar kegiatan terus terarah dan mencapai target yang optimal.

8. Evaluasi dan rencana tindak lanjut

Evaluasi ini bertujuan untuk melihat perkembangan program yang sudah dilaksanakan dan mengevaluasi pemahaman peserta terkait DaGuSiBu dengan membandingkan hasil pretest dengan postest. Tindak lanjut dari kegiatan ini adalah pendampingan kepada warga kelurahan Dukuh Menanggal untuk mensosialisasikan tentang $\mathrm{DaGuSiBu}$ ini kepada warga kelurahan dukuh menanggal yang lain agar tercapai program Gerakan Masyarakat Cerdas Menggunakan Obat dengan Benar sehingga terwujud pengobatan yang rasional. 


\section{PELAKSANAAN}

Pengabdian ini dilaksanakan Di lantai 2 gedung fakultas ilmu kesehatan universitas PGRI Adi Buana Surabaya. Total peserta yang hadir yaitu sejumlah 26 peserta.

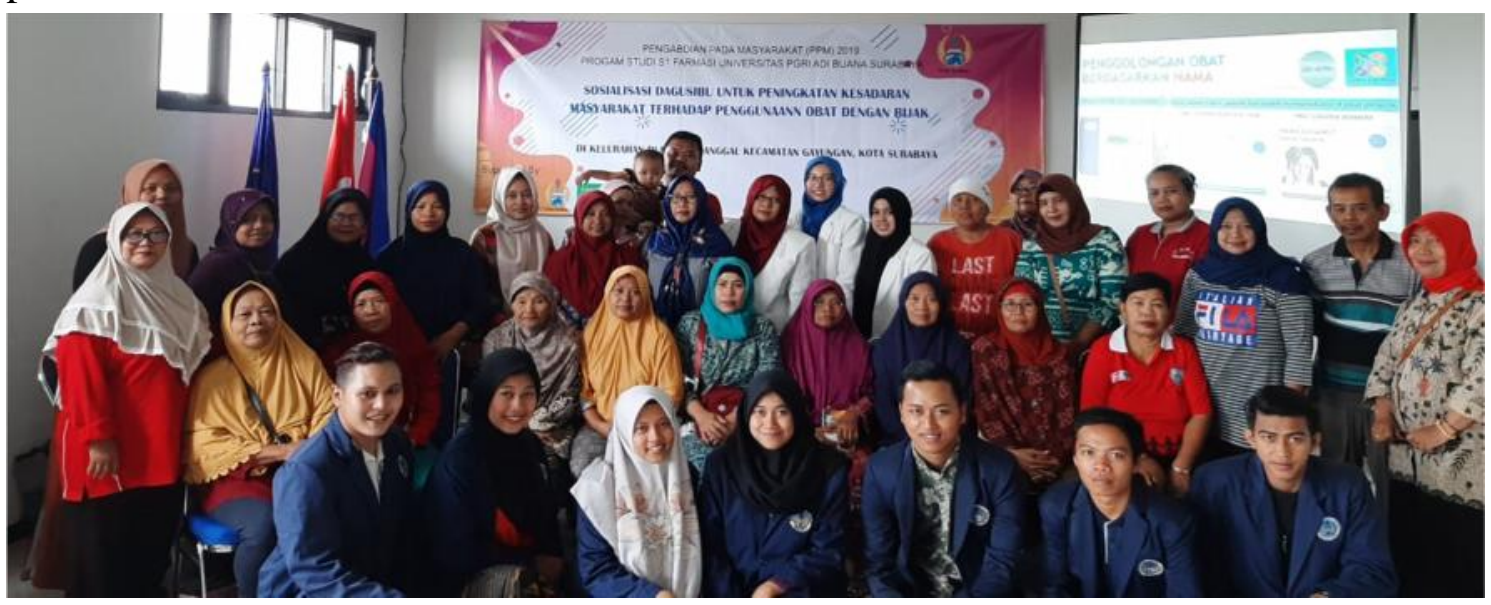

Gambar 1. Peserta Sosialisasi DAGUSIBU

Kegiatan pengabdian dimulai dengan pemaparan materi DAGUSIBU yang disampaikan oleh tim dosen. Masyarakat diberikan gambaran terlebih dulu mengenai masalah penyalahgunaan obat yang sering ada di masyarakat. Selanjutnya diberikan pemahaman mengenai tempat yang legal untuk membeli obat, penggolongan obat, obat-obat apa saja yang harus dibei dengan resep dokter, cara menyimpan obat yang benar, dan cara membuang obat yang benar.

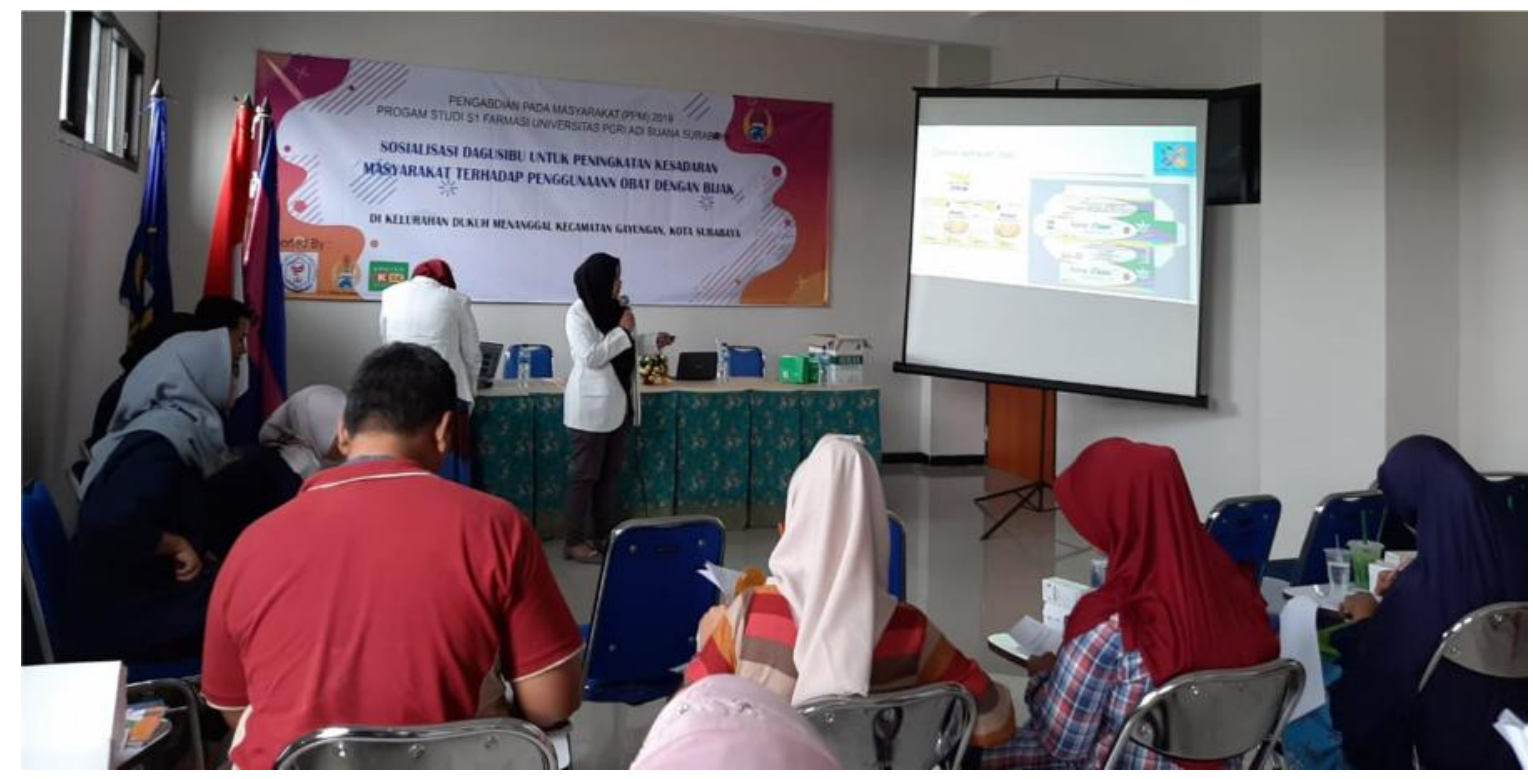

Gambar 2. Pemaparan Materi DAGUSIBU 
Setelah pemaparan materi, dilakukan sesi tanya jawab lalu dilanjutkan dengan pengisian kuisioner post sosialisasi untuk mengecek tingkat pemahaman warga apakah ada perubahan yang signifikan.

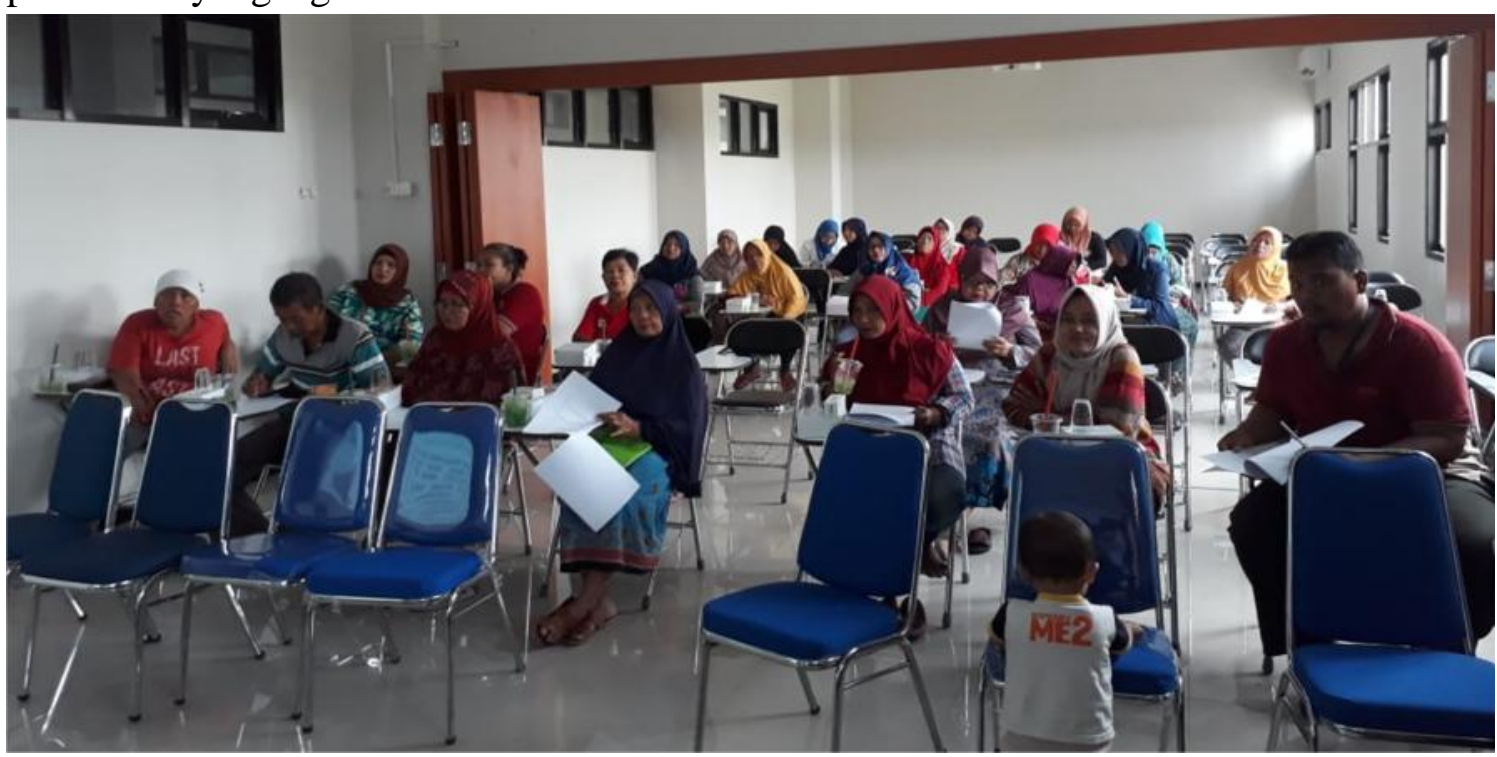

Gambar 3. Pengisian Kuisioner

\section{HASIL DAN LUARAN}

Kegiatan Pengabdian Masyarakat dengan judul "Sosialisasi Dagusibu (Dapat, Gunakan, Simpan, Buang) Sebagai Gerakan Masyarakat Cerdas Menggunakan Obat Dengan Bijak" dilaksanakan di lantai 2 gedung Fakultas Ilmu Kesehatan Universitas PGRI Adi Buana Surabaya pada hari Sabtu tanggal 22 Juni 2019. Sasaran pengabdian pada masyarakat ini yakni warga Kelurahan Dukuh Menanggal Surabaya yang berjumlah 26 orang. Tujuan kegiatan Pengabdian pada Masyarakat ini adalah untuk meningkatkan pengetahuan dan kesadaran masyarakat dalam mensukseskan gerakan masyarakat sadar obat (Gema Cermat) dalam hal ini DAGUSIBU obat yang rasional. Berikut pola perilaku cara mendapatkan, menggunakan, menyimpan, dan membuang obat warga kelurahan dukuh menanggal sebelum dilakukan sosialisasi berdasarkan data kuisioner yang tertuang pada table 1 sampai tabel 4 . 
Tabel 1. Pola Cara Mendapatkan Obat Yang Dilakukan Oleh Warga Kelurahan Dukuh Menanggal

\begin{tabular}{lcc}
\hline \multicolumn{1}{c}{ Cara Mendapatkan Obat } & Jumlah & Prosentase \\
\hline $\begin{array}{c}\text { Perilaku sakit } \\
-\quad \text { Mengobati sendiri }\end{array}$ & 5 & $19,2 \%$ \\
\hline$\quad$ Ke fasilitas Kesehatan & 21 & $80,8 \%$ \\
\hline $\begin{array}{l}\text { Jika mengobati sendiri, Macam } \\
\text { Obat yang digunakan }\end{array}$ & & \\
\hline$\quad \begin{array}{l}\text { Obat apa saja yang ada } \\
\text { dirumah }\end{array}$ & 5 & $100 \%$ \\
\hline $\begin{array}{l}\text { Sumber pengetahuan } \\
\text { mengobati sendiri }\end{array}$ & & \\
\hline$\quad \begin{array}{l}\text { Pengalaman sakit } \\
\text { sebelumnya }\end{array}$ & 3 & $60 \%$ \\
\hline$\quad$ Dari iklan & 1 & $20 \%$ \\
\hline$\quad$ Dari teman/ tetangga & 1 & $20 \%$ \\
\hline
\end{tabular}

Tabel 1 menggambarkan bahwa masyarakat jika sakit mereka akan langsung ke fasilitas kesehatan sehingga obat yang mereka dapatkan sudah pasti sumbernya, hanya sekitar 19\% yang mengobati sendiri. Pembelian obat atau mendapatkan obat sebaiknya memang di fasilitas kesehatan yang memang sumber resmi atau legal. Adanya pemberi informasi obat di fasilitas kesehatan dalam hal ini adalah apoteker maka dapat menjamin mutu serta kualitas obat, sehingga terhindar dari obat palsu atau obat kadaluarsa (Lutfiyati, 2017). Warga atau Responden yang mengobati sendiri, menggunakan obat apa saja yang ada dirumah berdasarkan pengalaman sakit sebelumnya (60\%), dari iklan (20\%), dan dari teman atau tetangga $(20 \%)$.

Tabel 2. Pola Cara Menggunakan Obat Yang Dilakukan Oleh Warga Kelurahan Dukuh Menanggal

\begin{tabular}{|c|c|c|c|}
\hline & Cara Menggunakan Obat & Jumlah & Prosentase \\
\hline \multicolumn{4}{|c|}{$\begin{array}{l}\text { Membaca Kemasan Obat sebelum } \\
\text { meminum }\end{array}$} \\
\hline- & Selalu & 15 & $57,7 \%$ \\
\hline- & Sering & 3 & $11,5 \%$ \\
\hline- & Kadang-kadang & 5 & $19,2 \%$ \\
\hline- & Jarang & 2 & $7,7 \%$ \\
\hline- & Tidak pernah & 1 & $3,8 \%$ \\
\hline \multicolumn{4}{|c|}{ Hal yang dibaca pada kemasan } \\
\hline- & Nama Obat & 6 & 23,1 \\
\hline- & Indikasi & 15 & $57,7 \%$ \\
\hline- & Cara pemakaian & 4 & $15,4 \%$ \\
\hline- & Dosis & 1 & $3,8 \%$ \\
\hline- & Peringatan & 0 & $0 \%$ \\
\hline \multicolumn{4}{|c|}{$\begin{array}{l}\text { Darimana mengetahui cara } \\
\text { menggunakan obat }\end{array}$} \\
\hline- & Iklan & 2 & $7,7 \%$ \\
\hline- & Kemasan & 5 & $19,2 \%$ \\
\hline- & Petugas kesehatan & 20 & $76,9 \%$ \\
\hline
\end{tabular}

Bagaimana cara menanggulangi

efek samping obat (ESO) 


\begin{tabular}{clcc}
\hline & Cara Menggunakan Obat & Jumlah & Prosentase \\
\hline- & Dibiarkan & 1 & $3,8 \%$ \\
\hline- & Memeriksakan ke dokter & 15 & $57,7 \%$ \\
\hline- & Menghentikan minum obat & 10 & $38,5 \%$ \\
\hline
\end{tabular}

Tabel 2 menggambarkan pola cara menggunakan obat warga kelurahan dukuh menanggal. Kebanyakan dari mereka selalu membaca kemasan obat sebelum meminumnya $(57,7 \%)$. Hanya 1 orang $(3,8 \%)$ yang mengaku tidak pernah membaca kemasan. Indikasi obat merupakan hal yang paling banyak $(57,7 \%)$ dibaca oleh responden dalam hal ini warga kelurahan dukuh menanggal. Mereka kebanyakan mengetahui cara menggunakan obat dari petugas kesehatan (77\%) sehingga kebenaran informasi kemungkinan besar sdh tersampaikan dengan jelas. Cara menanggulangi efek samping obat (ESO) yang dilakukan oleh warga kelurahan dukuh menanggal adalah dengan langsung memeriksakan ke dokter $(57,7 \%)$, menghentikan minum obat $(38,5)$, dan hanya sebesar 3,8\% yang menjawab dibiarkan saja.

Tabel 3. Pola Cara menyimpan Obat Yang Dilakukan Oleh Warga Kelurahan Dukuh Menanggal

\begin{tabular}{llcc}
\hline Cara Menyimpan Obat & Jumlah & Prosentase \\
\hline & & 7 & $26,9 \%$ \\
\hline- & Disimpan ditempat sejuk & 15 & $57,7 \%$ \\
\hline- & Dijauhkan dari matahari & 3 & $11,5 \%$ \\
\hline$-\quad$ Dijauhkan dari anak-anak & 1 & $3,8 \%$ \\
\hline$-\quad$ Simpan obat dalam & & \\
$\quad$ kemasan asli & & $34,6 \%$ \\
\hline$\quad$ Penyebab Obat rusak & 9 & $26,9 \%$ \\
\hline- & Penyimpanan yang salah & 7 & $38,5 \%$ \\
\hline- & Kadaluwarsa & 10 & \\
\hline
\end{tabular}

Tabel 3 menggambarkan pola menyimpan obat yang dilakukan oleh warga kelurahan dukuh menanggal. Dari semua opsi jawaban sebenarnya benar semua sehingga ditekankan pada masyarakat bahwa tetap harus melihat lagi di kemasan karena tiap obat mempunyai cara menyimpan yang berbeda-beda. Penyimpanan obat yang tidak memerlukan kondisi khusus sebaiknya disimpan pada kotak obat yang terlindung dari paparan sinar matahari langsung dan tidak terjangkau oleh anak-anak (Pujiastuti, 2019). Sedangkan alasan penyebab obat rusak semuanya sudah benar yaitu obat dapat rusak jika terkena matahari langsung, karena penyimpanan yang salah, dan obat telah kadaluwarsa. Penyimpanan obat yang tidak sesuai dapat menurunkan stabilitas obat yang pada akhirnya akan berpengaruh pada efektivitas obat tersebut dalam memberikan efek terapi (PP IAI, 2014). 
Tabel 4. Pola Cara Membuang Obat Yang Dilakukan Oleh Warga Kelurahan Dukuh Menanggal

\begin{tabular}{clcc}
\hline \multicolumn{1}{c}{ Cara Membuang Obat } & Jumlah & Prosentase \\
\hline$-\quad$ Dihancurkan dulu & 5 & $19,2 \%$ \\
\hline$-\quad \begin{array}{l}\text { Dibuang ke tempat } \\
\text { sampah }\end{array}$ & 15 & $57,7 \%$ \\
\hline$-\quad$ Dibuang ke got & 4 & $15,4 \%$ \\
\hline$-\quad$ Dibiarkan saja & 2 & $7,7 \%$ \\
\hline
\end{tabular}

Tabel 4 menggambarkan pola warga yang masih membuang obat tanpa dihancurkan terlebih dahulu. Hal ini dapt menjadi masalah penyalah gunaan obat oleh oknum yang tidak bertanggungjawab. Pemalsuan obat dapat terjadi jika obat yang tidak terpakai lagi dibuang begitu saja. Materi terakhir yang diberikan yaitu menjelaskan tentang cara membuang obat dengan benar supaya tidak disalahgunakan oleh orang lain. Pada saat akan membuang obat terlebih dahulu harus menghilangkan semua label dari wadah obat, untuk obat berbentuk padat harus dihancurkan terlebih dahulu sebelum dibuang, sedangkan untuk obat berbentuk cair dibuang ke dalam saluran air (PP IAI, 2014).

Setelah dilakukan sosialisasi DAGUSIBU terjadi peningkatan pengetahuan pada warga kelurahan Dukuh Menanggal yang setelah dilakukan evaluasi dengan uji statistik diperoleh $\mathrm{p}$ value sebesar 0,000 yang berarti peningkatan pengetahuan sebelum dan sesudah sosialisasi signifikan. Hal ini tertuang pada tabel 5 dan tabel 6 berikut ini :

Tabel 5. Perbandingan Hasil Kuisioner

\begin{tabular}{clcc}
\hline \multicolumn{1}{c}{ Pertanyaan } & \multicolumn{2}{c}{ Jumlah responden menjawab benar (n= 26) } \\
\cline { 2 - 3 } 1. & $\begin{array}{l}\text { Tempat membeli obat } \\
\text { yang legal }\end{array}$ & Sebelum & Sesudah \\
\hline 2. & $\begin{array}{l}\text { Logo obat yang harus } \\
\text { dibeli dengan resep }\end{array}$ & $21(80 \%)$ & $20(77 \%)$ \\
\hline 3. & $\begin{array}{l}\text { Cara menanggulangi } \\
\text { jika terjadi ESO }\end{array}$ & $7(27 \%)$ & $23(88 \%)$ \\
\hline 4. & Penyebab Obat rusak & $12(46 \%)$ & $22(85 \%)$ \\
\hline 5. Cara menyimpan obat & $10(38 \%)$ & $25(96 \%)$ \\
\hline yang benar & $\begin{array}{l}\text { Cara membuang obat } \\
\text { yang benar }\end{array}$ & $5(35 \%)$ & $26(100 \%)$ \\
\hline
\end{tabular}


Tabel 6. Hasil Uji Satistik Evaluasi Kegiatan Sosialisasi DAGUSIBU Pada Warga Kelurahan Dukuh Menanggal

\begin{tabular}{|c|c|c|c|c|c|c|c|c|}
\hline \multicolumn{9}{|c|}{ Paired Samples Test } \\
\hline \multicolumn{9}{|c|}{ Paired Differences } \\
\hline & \multirow[b]{2}{*}{ Mean } & \multirow[b]{2}{*}{ Std. Deviation } & \multirow{2}{*}{$\begin{array}{l}\text { Std. Error } \\
\text { Mean }\end{array}$} & \multicolumn{2}{|c|}{$\begin{array}{l}\text { 95\% Confidence Interval of the } \\
\text { Difference }\end{array}$} & \multirow[b]{2}{*}{$t$} & \multirow[b]{2}{*}{ df } & \multirow[b]{2}{*}{ Sig. (2-tailed) } \\
\hline & & & & Lower & Upper & & & \\
\hline Pair 1 bnr-salah & -64.23077 & 6.43309 & 1.26163 & -66.82915 & -61.63239 & -50.911 & 25 & .000 \\
\hline
\end{tabular}

\section{KESIMPULAN}

Pola perilaku warga kelurahan Dukuh Menanggal terkait cara mendapatkan, menggunakan, menyimpan, dan membuang obat masih kurang. Hal tersebut tercermin dari jawaban kuisioner pre sosialisasi yang dibagikan. Setelah dilakukan sosialisasi DAGUSIBU pengetahuan warga meningkat secara signifikan (peningkatan pengetahuan lebih dari 50\%) dan nilai signifikansi $\mathrm{p}$ value 0,000 yang artinya terdapat perbedaan pengetahuan yang bermakna antara sebelum dan sesudah sosialisasi.

\section{DAFTAR PUSTAKA}

Anonim. 2006. Pedoman penggunaan obat bebas dan bebas terbatas, Direktorat Bina Farmasi Komunitas dan Klinik. Ditjen Bina Kefarmasian dan Alat Kesehatan. Departemen Kesehatan RI. Jakarta.

Anonim. 2007. Pedoman pengelolaan obat publik dan perbekalan kesehatan di daerah perbatasan. Direktorat Bina Obat Publik dan Perbekalan Kesehatan. Jakarta.

Lutfiyati, H., Yuliatuti, F., Dianita, P.S..(2017). Pemberdayaan Kader PKK dalam Penerapan DAGUSIBU (Dapatkan, Gunakan, Simpan, dan Buang) Obat dengan Baik dan Benar. The 6th University Research Colloquium. Universitas Muhammadiyah Magelang. diakses tanggal 15 November 2018.http://journal.ummgl.ac.id/index.php/urecol/article/view/1562/672.

PP IAI. 2014. Pedoman Pelaksanaan Gerakan Keluarga Sadar Obat. Pengurus Pusat Ikatan Apoteker Indonesia. Jakarta

Pujiastuti, Anasthasia dan Monica Kristiani, 2019, Sosialisasi DAGUSIBU (Dapatkan, Gunakan, Simpan, Buang) obat dengan benar pada guru dan karyawan SMA Theresiana I Semarang, Indonesian Journal of Community Services, Indonesian Journal of Community Services, Vol 1 no.1 
Volume 4, Nomor 1, Maret 2020 